\title{
Relationship between the geometrical and structural properties of layered fractured rocks and their effective permeability tensor. A simulation study
}

\author{
H. Jourde ${ }^{a, *}$, P. Fenart ${ }^{b, 1}, M$. Vinches $^{b}$, S. Pistre ${ }^{a}$, B. Vayssade ${ }^{b}$ \\ a Laboratoire Hydrosciences, Université Montpellier II, Maison des Sciences de l'Eau, 300, Avenue Emile \\ Jeanbrau, 34090 Montpellier, France \\ ${ }^{\mathrm{b}}$ Centre des Matériaux de Grande Diffusion, Ecole des Mines d'Alès, 6 Avenue de Clavières, 30319 ALES Cedex, France
}

KEYWORDS

Coarse block permeability tensor; Layered fractured rock; Geometrical and structural properties; Field characterization

\begin{abstract}
Summary The influence of geometrical and structural properties of layered fractured rocks on their permeability tensor is investigated for an elementary volume at the meter scale. Various synthetic networks were generated with a three-dimensional model that incorporates a pseudo-random process controlled by mechanical rules of fracturing. The permeability is supposed to be a function of the discontinuities aperture in an impermeable matrix. Steady state, saturated laminar flow is assumed within discontinuities of constant aperture (parallel joint walls). For 81 networks associated to different sets of numerical parameters, the geometrical and structural properties are computed from 200 statistically equivalent simulations and averaged to asses the mean geometrical and structural properties. In a similar way, the mean permeability tensor associated to each network is calculated. Then, the effect of the geometrical and structural properties of the network on the permeability tensor values is studied. We show that some geometrical and structural properties may have non-negligible effects: The bedding perpendicular joint spacing and the bedding plane stopping capacity can induce more than one order of magnitude change in the permeability values, while other investigated properties (mean and standard deviation of the bedding perpendicular joints length distribution) have a very small influence. These results were compared with the permeability tensor inferred from one analytical model which provided permeability values of the same order of magnitude as those inferred from the numerical model. This model can thus be considered within the hierarchical procedure proposed to characterize rock mass permeability tensors in the field.
\end{abstract}

\footnotetext{
* Corresponding author.

E-mail address: Jourde@msem.univ-montp2.fr ( $\mathrm{H}$. Jourde).

1 Present address: Hydrofis, 10 Parc du Millénaire, 1025 rue Henri Becquerel, 34000 Montpellier, France.
} 


\section{Introduction}

Fluid flow modelling in fractured rocks is usually addressed by considering (i) discrete fracture models, (ii) equivalent continuum models using effective properties for discrete grids, or (iii) hybrid models that combine discrete large features and equivalent continuum grid properties (Lee et al., 2001).

In discrete fracture models (i), the matrix is generally assumed to be impermeable, which implies that the resulting permeability drops to zero when there is a loss in fracture connectivity (Bour and Davy, 1997; de Dreuzy et al., 2001). Because of their complexity, the use of discrete models is generally limited to small-scale problems (Jourde et al., 2002a).

The equivalent continuum models (ii) are widely used for field scale studies. Typically, these models include a limited number of regions in which physical properties (permeability or dispersivity) are assumed uniform. The physical properties computed from a fracture network are then averaged for the total rock volume, which includes fractures and matrix (Hsieh and Neuman, 1985; Long and Witherspoon, 1985; Jourde et al., 2002b).

Effective properties can be computed for a representative equivalent volume (REV) (Bear, 1972), in which the hydraulic properties change little with variation in rock volume. However, field measurements (Clauser, 1992; Cravero and Fidelibus, 1999; Schulze-Makuch et al., 1999), as well as numerical results (Margolin et al., 1998; Castaing et al., 2002; de Dreuzy et al., 2001) have shown that the permeability of a rock mass increases with its size. This scale effect has been explained as follows: when the volume of investigation increases, it either intersects more conductive discontinuities (morphological effect), or the relative arrangement of directional fracture sets changes (geometrical effect). These effects may lead to the absence of an REV at any scale (de Marsily, 1985; Pavlovic, 1998; Panda and Kulatilake, 1999).

Because of the scale dependency of geometrical and hydraulic properties, hybrid models (iii) combining discrete fracture and equivalent continuum models have been proposed (Clemo and Smith, 1989; Wen et al., 1991). The discrete part of the model describes the distribution of faults and the transfer within the "matrix", whose equivalent permeability is computed for an REV of the fractured rock mass compartmentalized between faults.

This later approach implies a detailed description of the rock mass, whose effective permeability properties can be addressed according to two different approaches: (i) either one uses analytical expressions while considering the statistical and geometrical properties of the discontinuity network (Snow, 1969; Sagar and Runchal, 1982; Oda, 1985;
Mania et al., 1998; Doolin and Mauldon, 2001). This formalism is well suited for networks of simple geometry, but is inefficient when the rock mass is characterized by a complex architecture of discontinuities (Paillet, 1985; Massonat, 1998; de Dreuzy et al., 2001; Castaing et al., 2002); (ii) Or one proceeds to steady state flow modelling throughout the rock mass, while considering various directions of flow depending on the given hydraulic gradient. The effective permeability is then determined in analogy with Darcy's law (Long et al., 1982; Long and Witherspoon, 1985; Long and Billaux, 1987; Massonat and Manisse, 1994). This approach is well suited for the study of various and complex natural fractured networks.

In this study, we used the both aforementioned approaches to determine the equivalent permeability properties of a layered fractured rock mass characterized by one set of bedding perpendicular joints and one set of bedding parallel joints.

This type of fracture network is characterized by a wide range of spatial relationships between bedding perpendicular and bedding parallel joints, which depend on the properties and thickness of the bedding surface infilling, and on the stress states during genesis and propagation of fractures. As a consequence, the persistence of bedding perpendicular joints across bedding planes varies highly, and this can be characterized statistically (Ladeira and Price, 1981; Helgelson and Aydin, 1991; Rives et al., 1992; Petit et al., 1994). This persistence is an important parameter for the permeability properties normal to bedding surfaces. In a similar way, the characteristics of geometrical (spacing and length distribution) and morphological (hydraulic aperture) parameters of bedding perpendicular joints should constrain the permeability normal to bedding.

The role of the aperture on the permeability normal to bedding and its consequences on the scale of an REV was studied in 2D by Doolin and Mauldon (2001). These authors pointed out that a longer chain has a greater chance of containing a weak link than a shorter chain. Similarly, since flow in the bed normal direction is controlled by the least permeable plane or bedding plane, adding layers increases the chance of an impermeable bed or bedding plane. The scale of homogeneity of the fracture system may not imply the scale of an REV. For a simple fracture geometry resembling courses of brick work, the scale of homogeneity of the fracture system bounds a single block of rock (brick), but the permeability drops rapidly as the number of layers increases (Doolin and Mauldon, 2001). These authors showed that, if an effective medium is assumed where the permeability changes very little with an increase in the number of layers, an order of magnitude difference between the scale of fracturing and the scale of an REV can be demonstrated. 
In this 3D study, there is no attempt to investigate whether the samples used are on a REV scale. The work is made at the scale of homogeneity of the fracture system (Doolin and Mauldon, 2001) which bounds a single block of rock (brick), that we referred to as an elementary volume.

As we wanted to focus essentially on the effect of geometrical and structural properties on the effective permeability tensor of a 3D block, we considered the same equivalent hydraulic aperture for the bedding perpendicular joints than for the bedding planes joints.

We first present the three-dimensional structural model (REZO3D) and discuss the variation range of geometrical and structural parameters encountered in rock masses made of one set of bedding perpendicular joints and one set of bedding parallel joints. Secondly, we expose the methodology for determining the effective permeability tensor components and analyse their sensitivity to the geometrical and structural properties of the synthetic network. The implications for field characterization of effective permeability properties of a rock mass are then discussed. Finally, we compare the results inferred from the three-dimensional model with permeability values obtained with a simple analytical model. The pertinence of this later model for estimating a 3D effective permeability tensor is then discussed.

\section{Materials and methods}

\section{Genesis of the discontinuity networks}

The three-dimensional model (REZO3D) allows the simulation of networks made of two orthogonal generations of bedding perpendicular joints in a tabular stratified medium. In this study, we consider networks made of one set of bedding perpendicular joints and one set of bedding parallel joints (bedding planes), which are continuous planes of infinite extent (Fig. 1). The later assumption is supported by field observation of sedimentary rocks.

Most fracture systems where one set is dominant have in general a second subordinate set forming a ladder pattern. The 'rungs' of the ladders help to connect fractures of the first set. The consideration of a second ladder pattern would imply considering also the connectivity change related to the connection between the first and second set of fractures, which may hide the structural properties effect. To better focus on the structural properties effect on the effective permeability value, we made the study with only one set of bedding perpendicular joints On the other hand,

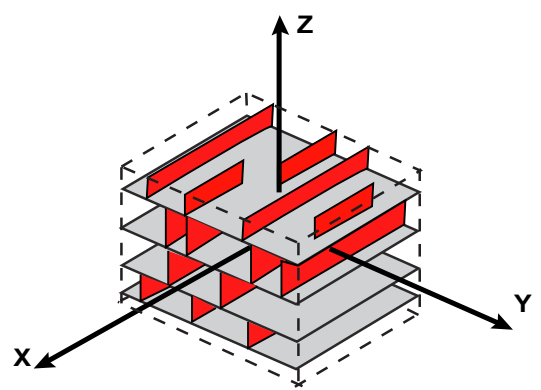

Figure 1 Sketch of the synthetic network with only a few bedding perpendicular joints represented. it is likely to encounter network geometries similar to the one considered in this study, especially when the local or regional stress state is such that it closes one family and opens the other family.

The model used is extensively described in Josnin et al. (2002) and is not the purpose of this paper. Hence, only the fundamentals of this model for our study will be summarized hereafter. It is based on a simple mechanical description of fractures propagation and interactions:

- A random process assigns the thickness of the strata, according to a lognormal distribution (mean thickness $\bar{T}$ and standard deviation $\sigma_{T}$ ).

- A random process assigns a potential length to the bedding perpendicular joints, according to a lognormal distribution (mean length $\bar{L}$ and standard deviation $\sigma_{L}$ ).

- A first set of bedding perpendicular joints (along the $X$ direction) grows from a given number of seeds $\left(N_{s}\right)$ defined by the user; seeds are randomly assigned to the strata, and are uniformly distributed within the designed stratum.

- The growth of bedding perpendicular joints accounts for (i) the potential length assigned to each seed; (ii) pseudo-mechanical rules inferred from the concept of shadow zone - a zone of stress relaxation around each fracture in which no new fracture can form (Price and Cosgrove, 1990; Rives et al., 1992) - reflecting mechanical interactions between bedding perpendicular joints during network genesis; the width $(2 E)$ of the shadow zone scales with bedding perpendicular joint height and is responsible for the observed correlation between bedding perpendicular joint spacing and bed thickness; (iii) bedding perpendicular joint propagation across bedding planes according to pseudo mechanical rules depending on three tests (crosscutting test, potential energy test, shadow zone test) described in Josnin et al. (2002). These tests depend on numerical parameters that we adjust to obtain a given bedding planes impedance I, which generates various stopping capacities SC of the bedding plane.

This three-dimensional approach of orthogonal joints networks in a tabular stratified medium was validated by comparing the model results with the properties of a natural joints network located in the Swiss Jura (Josnin et al., 2002). Although it is not a mechanical model, it allowed reproducing the spacing distribution of the natural joints network, ranging from a log-normal distribution below "saturation" to a normal distribution at "saturation", as observed on outcrops, without accounting for the density of joints as input parameters like in geostatistical models. These properties are inferred from mechanical rules (shadow zone, vertical persistency across sedimentary discontinuities), which differentiates our model from those that consider these conditions as input. Statistical data (joint length distribution, average spacing versus layer thickness, aspect ratio) are well accounted for by the model.

\section{Range of geometrical and structural parameters}

The aim of this study is the hierarchical classification of the role of these parameters on the effective permeability properties of a layered fractured rock mass of elementary dimension $D_{\mathrm{e}}\left(D_{\mathrm{e}} \times D_{\mathrm{e}} \times D_{\mathrm{e}}\right)$. We will consider an elementary 
volume of size unity $(1 \mathrm{~m} \times 1 \mathrm{~m} \times 1 \mathrm{~m})$ in the remaining of the paper.

Numerous studies have shown that the width of the shadow zone, which depends on the mechanical properties of the rock mass (Pollard and Aydin, 1988), scales with joint height and length (Ladeira and Price, 1981; Segall and Pollard, 1983; Bouissou et al., 1999; Pollard and Aydin, 1988; Renshaw and Pollard, 1994a,b). Therefore, we assigned a width value $(2 E)$ equal to $10 \%$ of the mean joint length $(\bar{L})$.

At the meter scale and within one lithology, the bedding plane density does not vary very much. We thus assumed that the rock mass volume contains the same number of bedding planes with a constant spacing for all the synthetic networks (mean thickness $\bar{T}=0.2 D_{\mathrm{e}}$, and standard deviation $\sigma_{T}=0$ ) to focus mainly on the parameters that vary widely depending on the considered rock mass (bedding perpendicular joint density, length distribution, stopping capacity of bedding planes).

For these later parameters, we defined a wide range of values in order to study various network geometries:

- Three values were chosen for $N_{s}$ (number of seeds) so that three different bedding perpendicular joint densities within the elementary volume are simulated.

- We adjusted the numerical parameters controlling the vertical propagation of bedding perpendicular joints across bedding parallel joints to obtain three bedding planes impedance I: (i) low impedance $I_{1}$ for high vertical propagation, (ii) intermediate impedance $I_{2}$ for intermediate vertical propagation, and (iii) high impedance $I_{3}$ for low vertical propagation.

- Three values were chosen for the mean length $\bar{L}$ $\left(0.5 D_{\mathrm{e}}, D_{\mathrm{e}}, 2 D_{\mathrm{e}}\right)$ of the bedding perpendicular joints length distribution.

- Three values were chosen for the reduced standard deviation $\left(\sigma_{L} / \bar{L}\right)$ of the bedding perpendicular joints length distribution to account for various degrees of dispersion, as shown by several field studies (Pollard and Aydin, 1988; Einstein and Baecher, 1983; Narr and Suppe, 1991; Odling, 1992): 50\% (low dispersion), 100\% (moderate dispersion), 200\% (high dispersion).

Table 1 summarizes the range of the parameter values that can take three different intensities. The combination of all the parameter intensities results in 81 different networks. For each of these networks, their geometrical and structural properties as well as their effective permeability tensor are computed from the average of 200 statistically equivalent synthetic networks. In the remaining of this paper, when we will refer to a property of one type of network, one must keep in mind that this is an averaged property computed from 200 statistically equivalent synthetic networks.

Fig. 2 shows a sketch illustrating the change in the geometrical and structural properties of the fracture networks according to the range of parameter intensities considered in this study.

\section{Geometrical analysis of the synthetic networks}

The fracture networks depend on input parameters that we refer to as numerical parameters, as opposed to the geo-
Table 1 (a) Numerical parameter values and intensities; (b) combinations of the numerical parameters intensities corresponding to the 81 types of network

\begin{tabular}{lllll}
\hline Intensity & \multicolumn{3}{l}{ Parameter } & \\
\cline { 2 - 5 } & $N_{\mathrm{s}}$ & $\bar{L}$ & $\sigma_{L}$ & $I$ \\
\hline Panel (a) & 15 & $0.5 D_{\mathrm{e}}$ & $0.5 \bar{L}$ & $I_{1}$ \\
1 & 30 & $1 D_{\mathrm{e}}$ & $1 \bar{L}$ & $I_{2}$ \\
2 & 60 & $2 D_{\mathrm{e}}$ & $2 \bar{L}$ & $I_{3}$
\end{tabular}

Panel (b)

No.

1

2

3

4

5

6

7

8

9

10

11

12

13

14

15

16

17

18

19

20

21

22

23

24

25

26

27

28

29

30

31

32

33

34

35

36

37

38

39

40

41

42

43

44

45

46

47

(b)

1

1

1

1

1

1

1

1

1

1

2

2

2

2

2

2

2

2

2

3

3

3

3

3

3

3

3

3 


\begin{tabular}{|c|c|c|c|}
\hline \multirow[t]{2}{*}{ Intensity } & \multicolumn{3}{|c|}{ Parameter } \\
\hline & $N_{s}$ & $\bar{L}$ & $\sigma_{L}$ \\
\hline 28 & 2 & 3 & 1 \\
\hline 49 & 2 & 3 & 2 \\
\hline 50 & 2 & 3 & 2 \\
\hline 51 & 2 & 3 & 2 \\
\hline 52 & 2 & 3 & 3 \\
\hline 53 & 2 & 3 & 3 \\
\hline 54 & 2 & 3 & 3 \\
\hline 55 & 3 & 1 & 1 \\
\hline 56 & 3 & 1 & 1 \\
\hline 57 & 3 & 1 & 1 \\
\hline 58 & 3 & 1 & 2 \\
\hline 59 & 3 & 1 & 2 \\
\hline 60 & 3 & 1 & 2 \\
\hline 61 & 3 & 1 & 3 \\
\hline 62 & 3 & 1 & 3 \\
\hline 63 & 3 & 1 & 3 \\
\hline 64 & 3 & 2 & 1 \\
\hline 65 & 3 & 2 & 1 \\
\hline 66 & 3 & 2 & 1 \\
\hline 67 & 3 & 2 & 2 \\
\hline 68 & 3 & 2 & 2 \\
\hline 69 & 3 & 2 & 2 \\
\hline 70 & 3 & 2 & 3 \\
\hline 71 & 3 & 2 & 3 \\
\hline 72 & 3 & 2 & 3 \\
\hline 73 & 3 & 3 & 1 \\
\hline 74 & 3 & 3 & 1 \\
\hline 75 & 3 & 3 & 1 \\
\hline 76 & 3 & 3 & 2 \\
\hline 77 & 3 & 3 & 2 \\
\hline 78 & 3 & 3 & 2 \\
\hline 79 & 3 & 3 & 3 \\
\hline 80 & 3 & 3 & 3 \\
\hline 81 & 3 & 3 & 3 \\
\hline
\end{tabular}

metrical and structural parameters (properties) resulting from measurements in the field. According to Table 1 these numerical parameters can take values corresponding to three different intensities. In order to analyse the effective permeability tensor of the simulated coarse blocks as a function of field parameters, we determine the geometrical and structural properties of the synthetic networks according to the various numerical parameters intensities.

These numerical parameters are (i) the number of seeds $N_{\mathrm{s}}$ that regulate bedding perpendicular joint density $\left(\mathrm{m}^{2} /\right.$ $\mathrm{m}^{3}$ ), (ii) the mean $\bar{L}$ and (iii) the standard deviation $\sigma_{L}$ of bedding perpendicular joint length distribution, and (iv) the numerical parameters which control the bedding plane impedance $l$.

The mean $\bar{L}$ and standard deviation $\sigma_{L}$ of the bedding perpendicular joint length distribution may be altered because of mechanical interactions between bedding perpendicular joints when propagation is not possible because of the shadow zone. However, previous work (Jourde, 1998; Josnin et al., 2002) has shown that the length distribution remains unchanged once the simulation has been performed. There- fore, these numerical parameters will be considered as geometrical and structural parameters (properties).

The stopping capacity of bedding parallel joints related to the bedding plane impedance, the bedding perpendicular joint spacing distribution, and the bedding perpendicular joint density, in contrast, result from the mechanical and pseudo-stochastic process of network generation. Therefore, we measured the sensitivity of these geometrical and structural properties to the variation of the numerical parameters by a statistical analysis of the synthetic networks.

\section{Stopping capacity of bedding planes}

In order to quantify its variability, the stopping capacity of bedding planes (SC) was calculated for the three bedding plane impedance $\left(I_{1}, I_{2}, I_{3}\right)$, while varying the other parameters. Fig. 3 shows the distribution of the stopping capacity SC of bedding planes, measured in \% of bedding perpendicular joints that crosscut one or several bedding planes. We observed a moderately high dispersion of this stopping capacity distribution for the lower bedding plane impedance $\left(\overline{\mathrm{SC}}=40 \%, \sigma_{\mathrm{SC}} / \overline{\mathrm{SC}}=34 \%\right)$, a lower dispersion for the intermediate bedding plane impedance $\left(\overline{\mathrm{SC}}=75 \%, \sigma_{\mathrm{SC}} / \overline{\mathrm{SC}}=9 \%\right)$ and almost no dispersion (distribution highly centred on the mean) for the higher bedding plane impedance $(\overline{\mathrm{SC}}=$ $\left.90 \%, \sigma_{\mathrm{SC}} / \overline{\mathrm{SC}}=2 \%\right)$.

As these stopping capacities of bedding planes have a normal distribution, we will express the three degrees of bedding plane impedance as a function of the mean stopping capacity of bedding planes $\overline{\mathrm{SC}}$. Accordingly, the synthetic networks will be referred to a mean stopping capacity of bedding planes of $40 \%\left(\overline{\mathrm{SC}}_{1}\right), 75 \%\left(\overline{\mathrm{SC}}_{2}\right)$ and $90 \%\left(\overline{\mathrm{SC}}_{3}\right)$, in the remaining of the paper.

\section{Bedding perpendicular joint density $D$}

Fig. 4a shows that the number of seeds $N_{\mathrm{s}}$, the mean stopping capacity of bedding planes $(\overline{\mathrm{SC}})$ and the mean length $\bar{L}$ of the bedding perpendicular joint length distribution, mainly control the bedding perpendicular joint density D:

- For a low $N_{\mathrm{s}}$ value (15), the higher the mean stopping capacity of bedding planes $(\overline{\mathrm{SC}})$, the lower the density. This is related to the fact that more bedding perpendicular joints are confined within one stratum when $\overline{S C}$ is high. In contrast, when $\overline{\mathrm{SC}}$ is low more bedding perpendicular joints develop across bedding planes, thereby increasing their surface, thus the bedding perpendicular joint density $D$.

- For a high $N_{s}$ value (60), the relationship between the mean stopping capacity of bedding planes $\overline{\mathrm{SC}}$ and the bedding perpendicular joint density $D$ disappears when the mean length $\bar{L}$ of the bedding perpendicular joint length distribution increases. Fig. $4 a$ shows that, when $\bar{L}$ is high $\left(\bar{L}_{3}\right)$, the bedding perpendicular joint density $D$ is the same for all the networks simulated with a given intensity of $N_{s}$, whatever the value of the mean stopping capacity of bedding planes $\overline{\mathrm{SC}}$. When $\bar{L}$ increases, mechanical interactions between bedding perpendicular joints become more likely and bedding perpendicular joint density $D$ decreases. 

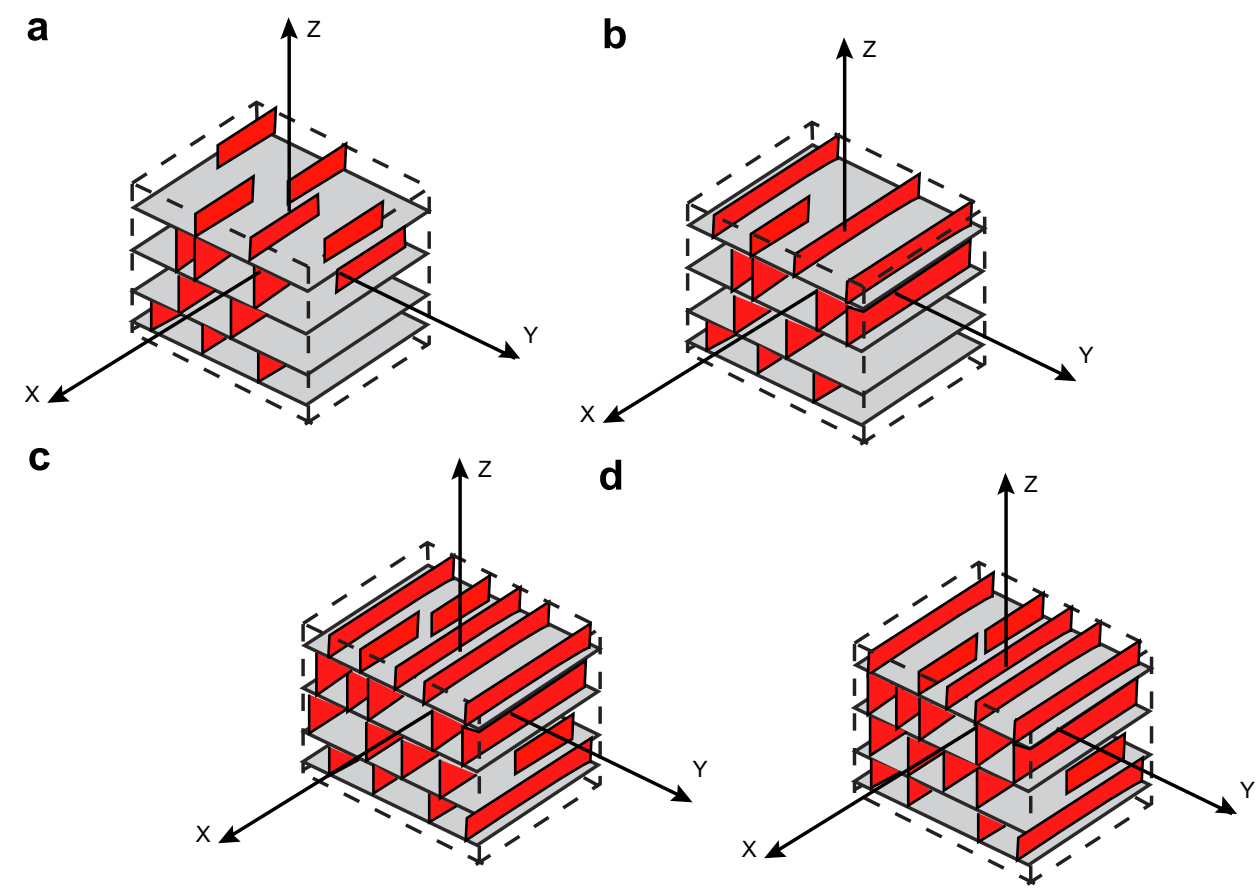

Figure 2 Sketch illustrating the range of simulated synthetic networks. (a) Low density, small bedding perpendicular joint length and high stopping capacity. (b) Low density, high bedding perpendicular joint length and high stopping capacity of bedding planes. (c) High density, high bedding perpendicular joint length and high stopping capacity of bedding planes. (d) High density, high bedding perpendicular joint length and low stopping capacity of bedding planes.

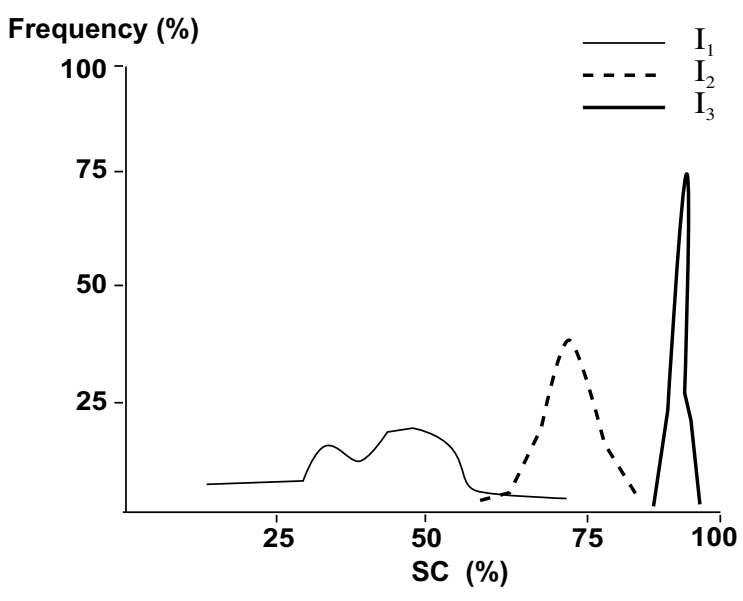

Figure 3 Distribution of the stopping capacity of the bedding planes (SC) calculated for each intensity $l_{i}$ of the bedding plane impedance.

- For an intermediate $N_{s}$ value (30), the bedding perpendicular joint density $D$ is related with both the mean stopping capacity of bedding planes $\overline{\mathrm{SC}}$ and the mean length $\bar{L}$. The higher the mean stopping capacity of bedding planes $\overline{\mathrm{SC}}$ the lower the density $D$, and the higher $\bar{L}$ the lower the density $D$.

For a given value of the mean length $\bar{L}$, the bedding perpendicular joint density $D$ thus increases when the number of seeds $N_{s}$ increases. Therefore, the synthetic networks generated with $N_{s_{1}}=15, N_{s_{2}}=30$ and $N_{s_{3}}=60$ will be re- ferred to as networks of low, intermediate and high density, in the remaining of the paper.

The density of bedding perpendicular joints that crosscut the whole network $\left(D_{\mathrm{fc}}\right)$ is important since it controls the effective permeability along the bedding perpendicular joint strike ( $X$-direction). Fig. $4 \mathrm{~b}$ shows that the mean length $\bar{L}$ and the number of seeds $N_{\mathrm{s}}$ mainly control this density $D_{\mathrm{fc}}$. For a given intensity $\left(\bar{L}_{i}\right)$ of the bedding perpendicular joint length, $D_{\mathrm{fc}}$ increases when $N_{\mathrm{s}}$ increases. For a given intensity $\left(N_{\mathrm{s}_{i}}\right)$ of the number of seeds, $D_{\mathrm{fc}}$ increases when the mean length $\bar{L}$ increases.

\section{Bedding perpendicular joint spacing $S$}

Fig. $4 \mathrm{C}$ shows that the mean bedding perpendicular joint spacing $(S)$ is correlated with the mean perpendicular joint length $(\bar{L})$. Indeed, the more $N_{\mathrm{s}}$ increases, the stronger this correlation because of the assumed proportionality between $2 E$ and $\bar{L}$.

For a low $N_{s}$ value (15), there is a strong correlation between the mean bedding perpendicular joint spacing $(S)$ and the mean stopping capacity of the bedding planes $(\overline{\mathrm{SC}})$. Indeed, a low $\overline{\mathrm{SC}}$ value (40\%) is related to bedding perpendicular joints developing across bedding planes in adjacent strata, which increases the mean number of bedding perpendicular joints within strata and thus reduces their mean spacing $S$.

As spacing distributions are resulting from random processes, they are carefully analysed for each network. For a given network, the mean bedding perpendicular joint spacing $(S)$ does not vary significantly from one stratum to another. On the contrary, it may vary highly from 
a
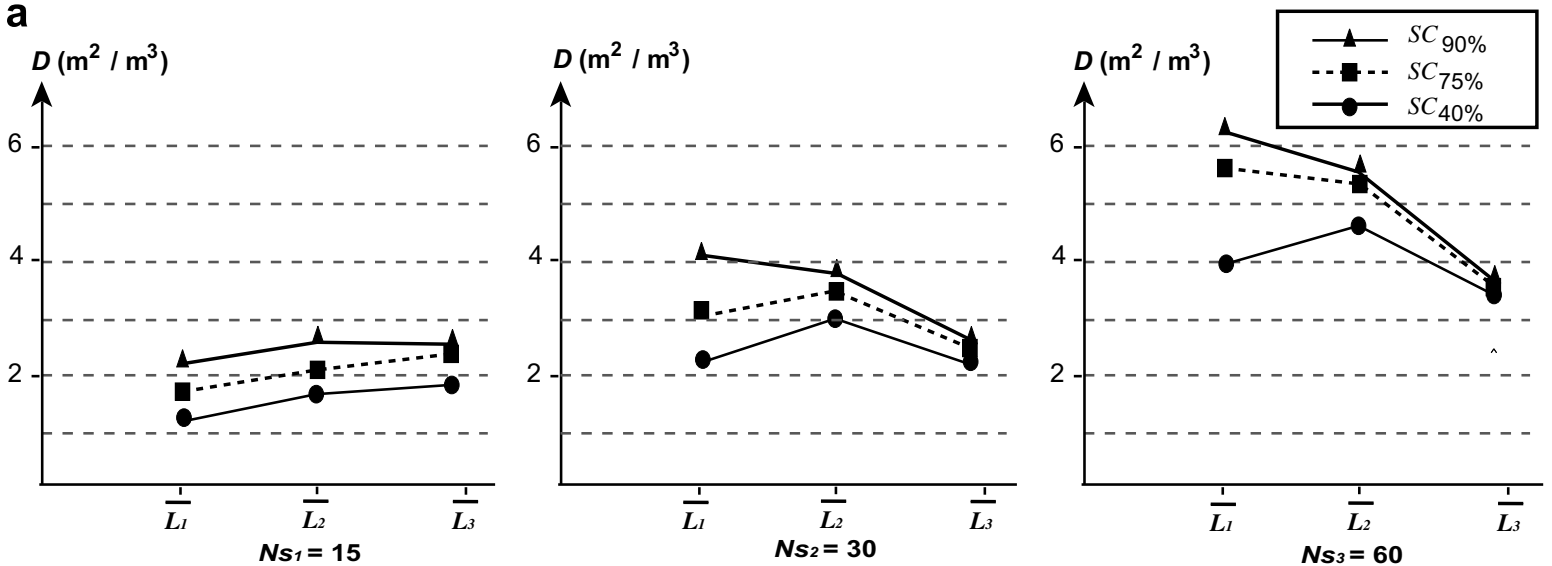

b

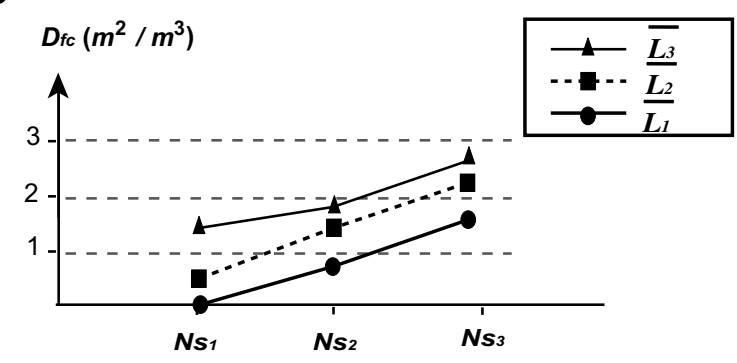

C
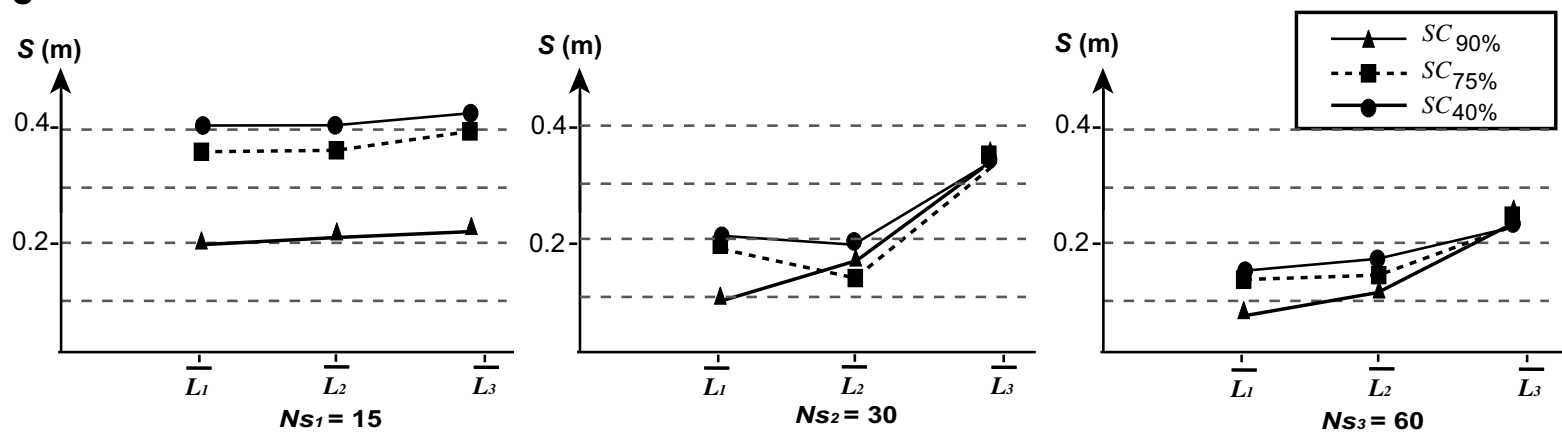

d

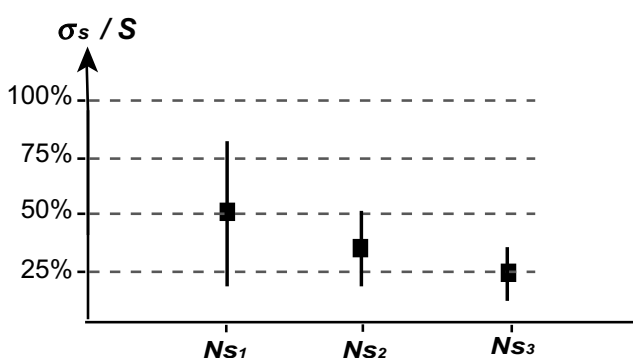

Figure 4 Statistics on the geometrical and structural properties of the networks. (a) Density of bedding perpendicular joints $D$; (b) density of bedding perpendicular joints crosscutting the elementary volume $D_{\mathrm{fc}}$; (c) mean spacing of bedding perpendicular joint, $S$; (d) variability of spacing distributions $\left(\sigma_{S} / S\right)$.

one network to another (Fig. 4c). The number of seeds $N_{\mathrm{s}}$ controls this variability since the reduced standard deviation of the spacing distribution $\left(\sigma_{\mathrm{S}} / S\right)$ decreases as $N_{s}$ increases (Fig. 4d). The reduced standard deviation varies between $20 \%$ and $80 \%$ for $N_{s_{1}}=15$, between $15 \%$ and $45 \%$ for $N_{s_{2}}=30$ and between $15 \%$ and $35 \%$ for $N_{\mathrm{s}_{3}}=60$.

The reason is the pseudo-stochastic processes that control the initiation and growth of the bedding perpendicular joints that predominate when the network density is low. 
Indeed, when the number of seeds $N_{s}$ is low, there is a lower probability of interactions between bedding perpendicular joints. Therefore, $2 E$ does not control the bedding perpendicular joint spacing $(S)$ as in the case of "saturated" networks.

\section{Effective permeability components determination}

Because of the network geometry, the effective permeability tensors of the coarse blocks are symmetric. They can thus be characterized by their principal components along the $X$-direction (common to bedding perpendicular and bedding parallel joints), the $Y$-direction (normal to bedding perpendicular joint) and the Z-direction (normal to bedding parallel joints) that we will refer to as $k_{x}, k_{y}$ and $k_{z}$, respectively.

The main premise of this study is that the aperture is small enough to allow joints (bedding perpendicular joints and bedding planes) to be treated as planar high-flow regions embedded in an impermeable matrix. The flow velocity is assumed to be small enough in the joints so that no head loss occurs at joints intersections, as supported by laboratory testing (Wilson, 1970).

Flow is treated as a two-dimensional Darcy flow, similar to the flow between two parallel plates.

Equations for the average velocity $\boldsymbol{V}$ and discharge $q$ per unit width of a parallel plate conduit are derived from the Navier-Stokes equations (Snow, 1969):

$\boldsymbol{V}=-\frac{b^{2}}{3} \frac{\mathrm{g}}{v} \mathrm{~J}$ and $q=-\frac{2}{3} b^{3} \frac{\boldsymbol{g}}{v} \mathrm{~J}$

where $\boldsymbol{g}$ is the gravitational acceleration, $v$ is the kinematic viscosity, $J$ is the projected gradient of potential, and $b$ is the half aperture of the parallel plate conduit.

Although fractures which are parallel and perpendicular to bedding seldom have similar apertures, we assume for convenience that bedding perpendicular joints and bedding planes joints have the same hydraulic aperture $a_{\mathrm{h}}=2 b$, so that the influence of structural properties may be better identified.

The average velocity $\boldsymbol{V}$ per unit width is then given by

$\boldsymbol{V}=-\frac{a_{\mathrm{h}}^{2}}{12} \frac{\mathrm{g}}{\mathrm{v}} \mathrm{J}$

This average velocity can also be explained as a function of the permeability $k$ of the discontinuity:

$\boldsymbol{V}=-k \frac{\boldsymbol{g}}{v} \mathrm{~J}$

Accordingly, the relationship between the permeability $k$ of the discontinuity and the hydraulic aperture $a_{\mathrm{h}}$ is

$k=\frac{a_{\mathrm{h}}^{2}}{12}$.

It is well known that the permeability of fractured rock is sensitive to the magnitude of fracture apertures. In joints networks, Doolin and Mauldon (2001) showed for example that each order of magnitude reduction of the bedding plane aperture reduces the bed normal permeability by three orders of magnitude.

At the chosen scale of study (meter scale), bedding perpendicular joints and bedding parallel joints generally have a hydraulic aperture that ranges between 0.01 and $0.6 \mathrm{~mm}$ (Belfield and Sovich, 1994; Bandis, 1980; Hakami, 1998; Esaki et al., 1995; Marret et al., 1999). The resulting fracture permeability per unit width $k$ would then vary between $8.3 \times 10^{-17} \mathrm{~m}^{2}$ and $1.8 \times 10^{-11} \mathrm{~m}^{2}$, thus over six order of magnitude. As we made the assumption that the discontinuities have the same hydraulic aperture $a_{\mathrm{h}}$, the directional components of the effective permeability tensor $\left(k_{x}, k_{y}\right.$ and $k_{z}$ ) would vary within the same range of magnitude. If we determine the effective permeability tensor of one type of network with a given hydraulic aperture, we can thus deduce the permeability tensor of the same network with another hydraulic aperture.

Although the aperture of the discontinuities is the factor that mainly influences the values of the effective permeability tensor directional components, it is not the purpose of this paper which will mainly focus on the influence of structural parameters on the effective permeability tensor for one given hydraulic aperture.

\section{Results and discussion}

For each synthetic network, we numerically determine (as an output of the structural model REZO3D) the density $D_{\mathrm{fc}}$ $\left(\mathrm{m}^{2} / \mathrm{m}^{3}\right)$ of bedding perpendicular joints crosscutting the elementary volume (cf. Fig. 4b). Given the assumed number of strata, the bedding planes density within the rock mass of unit volume remains $D_{\mathrm{bp}}=4 \mathrm{~m}^{2} / \mathrm{m}^{3}$ for all the networks.

An analytical expression accounting for these two parameters $\left(D_{\mathrm{fc}}\right.$ and $\left.D_{\mathrm{bp}}\right)$, the equivalent hydraulic aperture $a_{\mathrm{h}}$ $(0.08 \mathrm{~mm})$ and the corresponding permeability $k(4.3 \times$ $10^{-14} \mathrm{~m}^{2}$ ) is then used to calculate the $k_{x}$ and $k_{y}$ effective permeability components.

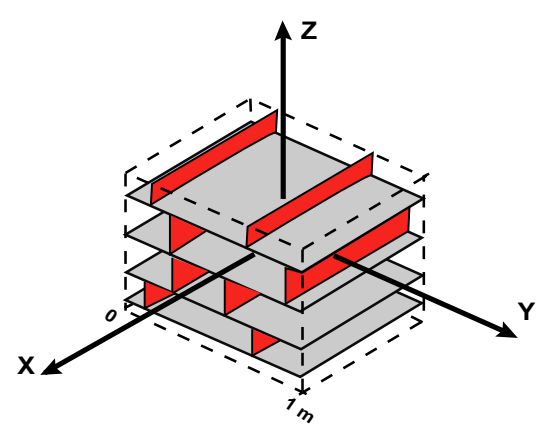

Figure 5 Sketch showing the flow paths along the $x$-direction.

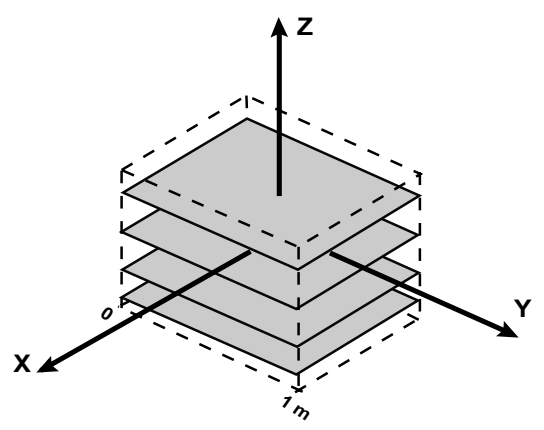

Figure 6 Sketch showing the flow paths along the $y$-direction. 
a

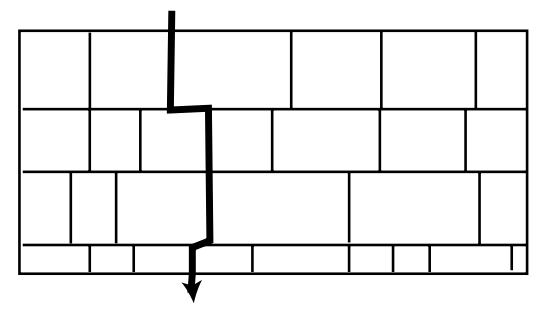

b

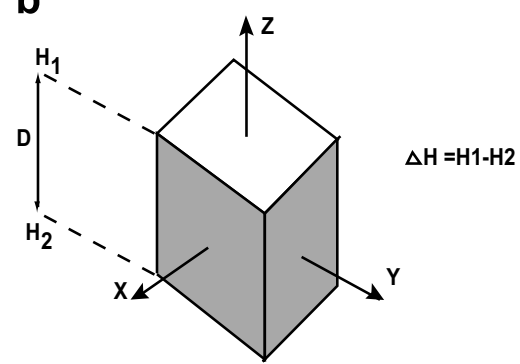

Figure 7 (a) Sketch showing the flow paths along $y$-direction normal to bedding. (b) Boundary conditions for flow simulations.

Along the $X$-direction, only bedding plane and bedding perpendicular joints which are crosscutting the entire network control the flow (Fig. 5).

Thus, the effective permeability $k_{x}\left(\mathrm{~m}^{2}\right)$ can be expressed as follows:

$k_{\mathrm{x}}=\left(D_{\mathrm{bp}}+D_{\mathrm{fc}}\right) \times a_{\mathrm{h}} \times k$.

Along the $Y$-direction, flow occurs within the bedding planes only (Fig. 6). Thus, the effective permeability $k_{y}\left(\mathrm{~m}^{2}\right)$ can be expressed as follows:

$k_{\mathrm{y}}=D_{\mathrm{bp}} \times a_{\mathrm{h}} \times k$.

As the density of the bedding planes joints is assumed constant, $k_{y}$ will remain the same and will be considered only for comparison with the other effective permeability components $k_{\mathrm{x}}$ and $k_{\mathrm{z}}$.

Flow along the Z-direction, within the bedding perpendicular joints normal to bedding and the bedding planes, is complex because of the three-dimensional aspect of the problem. Indeed, $k_{z}$ depends on all the parameters that control the density of bedding perpendicular joints and their mechanical interactions with the bedding planes (Fig. 7a). Thus, the use of an analytical formalism to determine the effective permeability $k_{z}$ of the three-dimensional networks is more difficult to apply. Therefore we performed steady state fluid flow modelling while accounting for fluid flow within all discontinuities of the network. Steady state flow rate is calculated through the network with the following boundary conditions: No flow boundary condition (Neuman condition) on the $(X Z)$ and $(Y Z)$ planes and prescribed potential head boundary (Dirichlet condition) on both $(X Y)$ planes at the upper ( $\mathrm{H} 1)$ and lower $(\mathrm{H} 2)$ boundaries (Fig. 7b).

Then, by analogy with Darcy's law, the effective permeability $k_{z}$ is determined by considering the calculated flow rate $q$ and the gradient $J\left(\Delta H / D_{\mathrm{e}}\right)$ :

$q=A \boldsymbol{V}=-k A \frac{g}{v} J$

with $A$, the section normal to flow, $g$ the gravitational acceleration, $v$ the kinematic viscosity.

The effective permeability $k_{z}$ is then inferred from the calculated flow rate $q$ :

$k_{z}=-\frac{q}{A \frac{g}{v}}$.

\section{Effective permeability $k_{x}$}

Fig. 8 shows that $k_{x}$ slightly increases when the bedding perpendicular joint density (expressed as a function of $N_{s}$ ) or the mean bedding perpendicular joint length $(\bar{L})$ increases. The combined effect of the later parameters on $k_{x}$ can generate a $60 \%$ increase in permeability. This is related to the proportionality of $k_{x}$ to the density of all discontinuities allowing flow along the $X$-direction. As the density of bedding planes $D_{\mathrm{bp}}$ remains constant for all simulations, only the density $D_{\mathrm{fc}}$ of the bedding perpendicular joints crosscutting the entire elementary volume, which varies between 0 and $3 \mathrm{~m}^{2} / \mathrm{m}^{3}$ (cf. Fig. $4 \mathrm{~b}$ ), induces the $60 \%$ variation in $k_{x}$.

If the density of bedding planes $D_{\mathrm{bp}}$ is lower, the influence of the bedding perpendicular joints crosscutting the entire network becomes dominant and the density $D_{\mathrm{fc}}$ controls $k_{\mathrm{x}}$.

We performed a global analysis of the variance of $k_{x}$ as a function of $N_{s}, \bar{L}, \sigma_{L}, \overline{S C}$ in order to quantify the influence of those parameters.

$k_{x}=f\left[N_{s}, \bar{L}, \sigma_{L}, \overline{S C}\right]$.

This analysis aims at estimating the rate of variation of $k_{x}$ with respect to these parameters. Each type of network is generated according to one possible combination of various parameters that are assigned three intensities (cf. Table 1). Each parameter $p$ is thus assigned three effects $E_{p 1}, E_{p 2}, E_{p 3}$, with $E_{p i}$ referring to the effect of the parameter $p$ when its intensity is $i$.

The effect $E_{p i}$ is quantified by calculating the average value of $k_{x}$ for all the networks generated with the intensity $i$ for the parameter $p$, whatever the intensity of the other parameters. For example, the effect $E_{N_{s,}}$ for the bedding perpendicular joint density $\left(N_{s}\right)$ with the intensity $i$ is given as follows:

$E_{N_{s_{i}}}=\frac{\sum k_{x}\left[N_{s_{i}}, \bar{L}_{j}, \sigma_{L k}, \overline{\mathrm{SC}}_{l}\right]}{n}$

with $n$ the number of networks analysed, and $j, k, l$ the intensities $(1,2$, or 3$)$ of the other parameters. Its value equals the mean of the permeability values calculated for the 27 type of synthetic networks for which the bedding perpendicular joint density is $N_{s_{i}}$.

The rate of variation $\left(R_{\mathrm{v}}\right)$ related to one parameter $p$, is defined as the ratio between $E_{p \max }$ and $E_{p \min }$, the maximal and minimal value of the effect, respectively. It can thus be used to quantify the influence of this parameter $p$ on the permeability value.

Table 2 shows the rate of variation $\left(R_{\mathrm{v}}\right)$ for each parameter on which $k_{x}$ depends on. The bedding perpendicular joint density $\left(N_{s}\right)$ and the mean perpendicular joint length $(\bar{L})$ have a noticeable effect, since they may induce a change of almost $50 \%$ in $k_{x}$. The standard deviation of the perpendicular joint length distribution $\left(\sigma_{L}\right)$, the mean stopping capacity of 


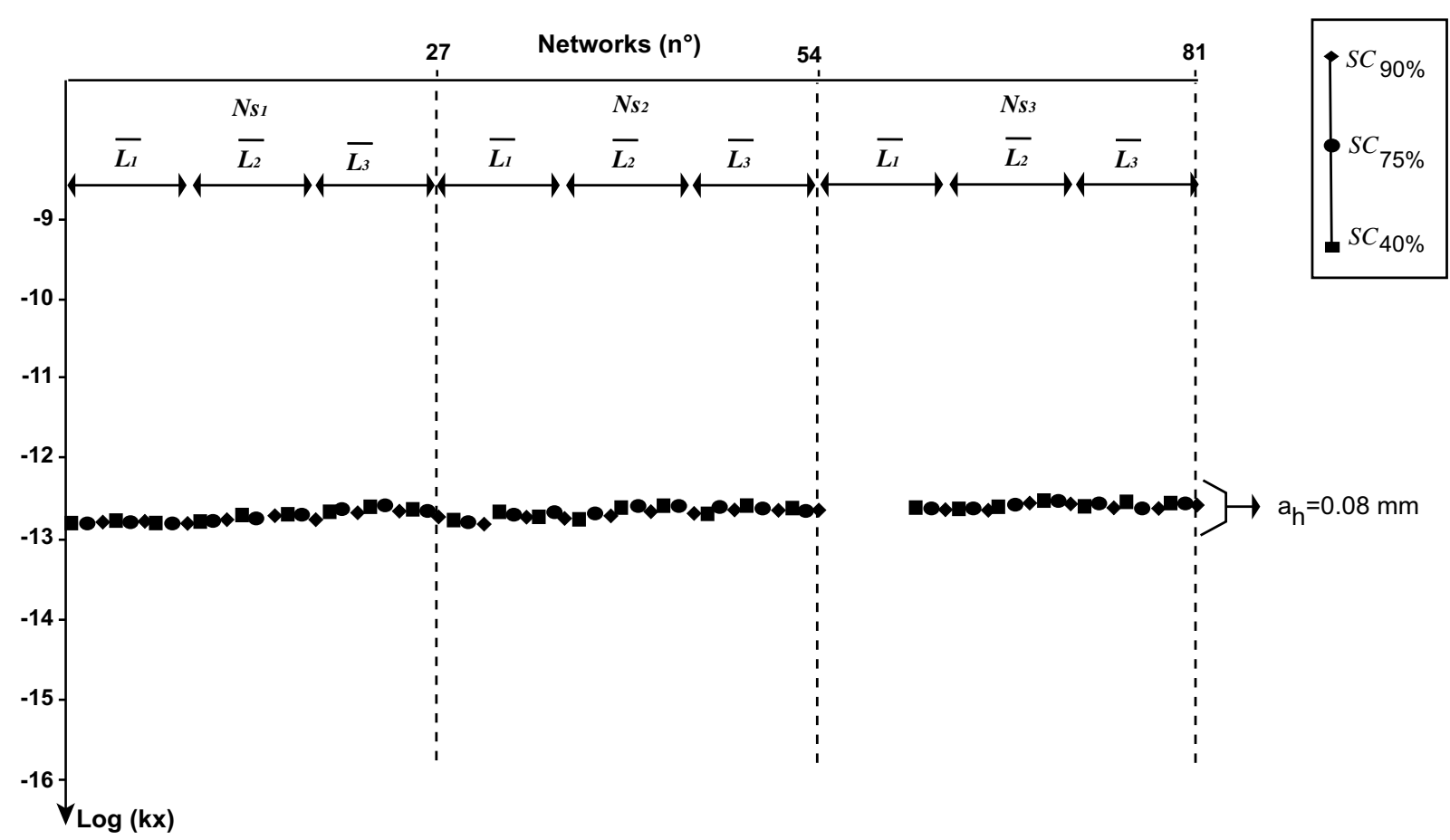

Figure 8 Permeability component $k_{x}$ of each synthetic network. Nine values of permeability, resulting from the combination of the three mean stopping capacity of bedding planes $\overline{\mathrm{SC}}$ and the three standard deviation $\sigma_{L_{i}}$, are associated to each mean length $\bar{L}_{i}$ of the bedding perpendicular joint spacing distribution.

Table 2 Global analysis of the $k_{x}$ permeability variations

\begin{tabular}{|c|c|c|c|c|}
\hline \multirow[t]{2}{*}{$E_{p i}$} & \multicolumn{4}{|l|}{$p$} \\
\hline & $N_{s}$ & $\bar{L}$ & $\sigma_{L}$ & $\overline{\mathrm{SC}}$ \\
\hline \multicolumn{5}{|c|}{ Panel (a) } \\
\hline$E_{p 1}$ & $1.9 E-13$ & $1.8 \mathrm{E}-13$ & $1.9 E-13$ & $2.1 \mathrm{E}-13$ \\
\hline$E_{p 2}$ & $2.1 \mathrm{E}-13$ & $2.1 \mathrm{E}-13$ & $2.2 \mathrm{E}-13$ & $2.2 \mathrm{E}-13$ \\
\hline$E_{p 3}$ & $2.6 E-13$ & $2.4 \mathrm{E}-13$ & $2.2 \mathrm{E}-13$ & $2.1 \mathrm{E}-13$ \\
\hline \multicolumn{5}{|c|}{ Panel (b) } \\
\hline$R_{\mathrm{v}}$ & 1.36 & 1.33 & 1.16 & 1 \\
\hline
\end{tabular}

(a) Parameters effect; (b) rate of variation $\left(R_{\mathrm{v}}\right)$ related to the parameters.

bedding planes $(\overline{\mathrm{SC}})$, in contrast, have a negligible effect on $k_{x}$.

\section{Effective permeability $k_{z}$}

Fig. 9 displays $k_{z}$ values calculated for all synthetic networks. All the parameters significantly influence $k_{z}$, except the standard deviation of the perpendicular joint length distribution $\left(\sigma_{L}\right)$.

The mean stopping capacity of bedding planes $(\overline{\mathrm{SC}})$ and the mean perpendicular joint length $(\bar{L})$ have a high influence on $k_{z}$, which is also strongly dependent on the bedding perpendicular joint density $\left(N_{\mathrm{s}}\right)$ :

- For networks of high bedding perpendicular joint density $\left(N_{s_{3}}=60\right), k_{z}$ highly decreases when the mean perpendicular joint length $(\bar{L})$ increases because the bedding per- pendicular joint density decreases (cf. Fig. 4a). For such networks, there is almost no link between the mean stopping capacity of bedding planes $\overline{\mathrm{SC}}$ and $k_{z}$.

- For networks of moderate and low density $\left(N_{s_{2}}=30\right.$ and $\left.N_{s_{1}}=15\right)$, in contrast, $k_{z}$ is less sensitive to $\bar{L}$. On the contrary, the mean stopping capacity of bedding planes $\overline{\mathrm{SC}}$ may induce a one order of magnitude change in $k_{z}$.

- Whatever the network density, the influence of the mean stopping capacity of bedding planes $(\overline{\mathrm{SC}})$ decreases as the mean perpendicular joint length $(\bar{L})$ increases.

The analysis of variance for $k_{z}$ confirms the previous observations as illustrated by the rate of variation $R_{\mathrm{v}}$ (Table 3):

- The bedding perpendicular joint density $\left(N_{\mathrm{s}}\right)$ and the mean stopping capacity of bedding planes $(\overline{\mathrm{SC}})$ have a non-negligible influence on $k_{z}$, which may increase by a factor of 2-4.

- The mean perpendicular joint length $(\bar{L})$ has a smaller influence on $k_{z}$ than the other parameters.

- The standard deviation of the perpendicular joint length distribution $\left(\sigma_{L}\right)$ has a minor influence.

As the influence of the mean stopping capacity of bedding planes $(\overline{\mathrm{SC}})$ and the mean perpendicular joint length $(\bar{L})$ on $k_{\mathrm{z}}$ is strongly dependent on the intensity of the bedding perpendicular joint density $\left(N_{s}\right)$, we performed a more detailed analysis of the $k_{z}$ variation. We thus calculated the mean effect of the parameters for the three sets of networks characterized by the same bedding perpendicular joint density $N_{\mathrm{s}}$. For example, $E_{L 1-N_{s_{1}}}$ is the effect corre- 


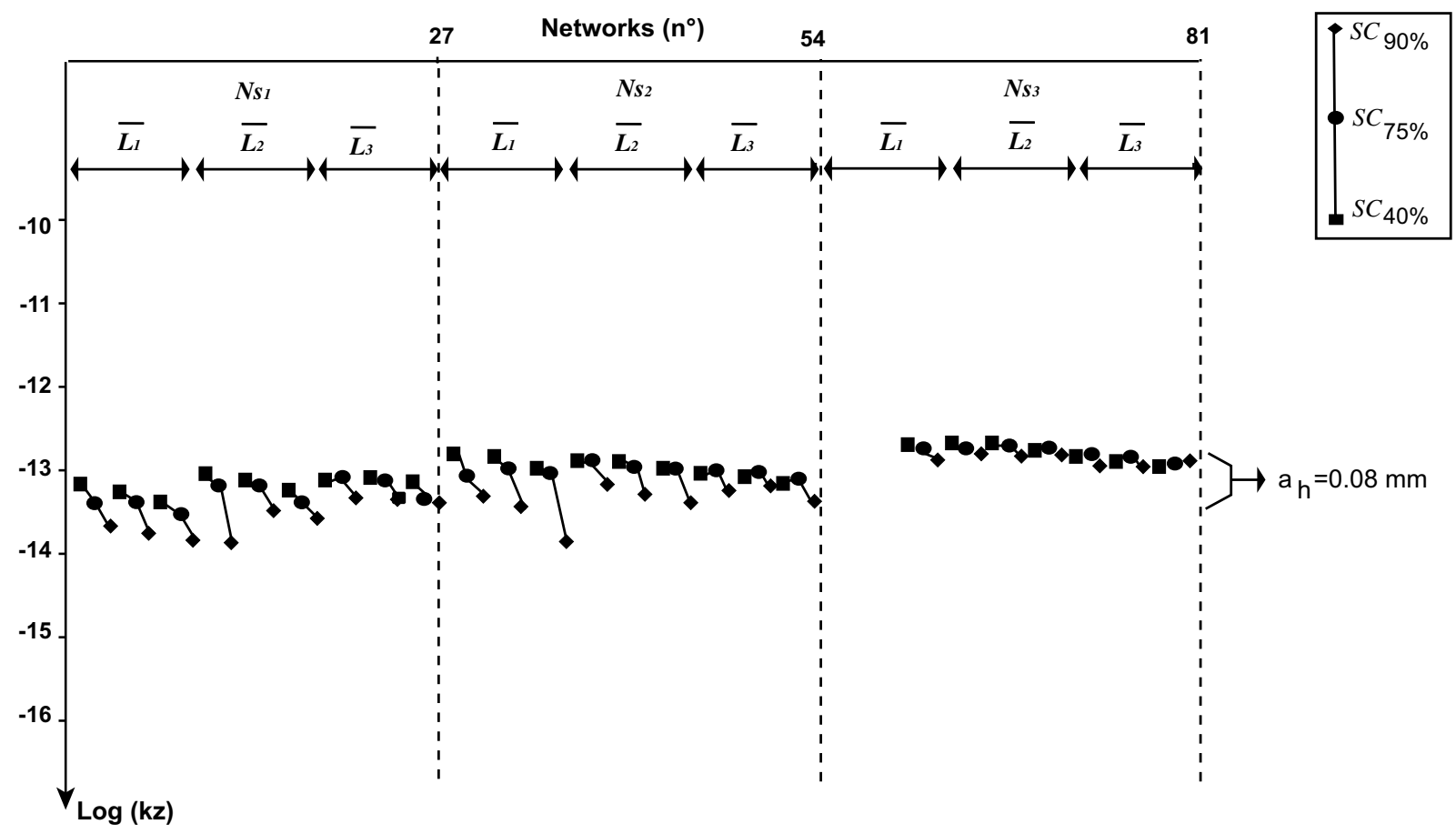

Figure 9 Permeability component $k_{z}$ represented for all the simulations. Nine values of permeability, resulting from the combination of the three mean stopping capacity of bedding planes $\overline{\mathrm{SC}}$ and the three standard deviation $\sigma_{L_{i}}$, are associated to each mean length $\bar{L}_{i}$ of the bedding perpendicular joint spacing distribution.

Table 3 Global analysis of the $k_{z}$ permeability variations

\begin{tabular}{|c|c|c|c|c|}
\hline \multirow[t]{2}{*}{$E_{p i}$} & \multicolumn{4}{|l|}{$p$} \\
\hline & $N_{\mathrm{s}}$ & $\bar{L}$ & $\sigma_{L}$ & $\overline{\mathrm{SC}}$ \\
\hline \multicolumn{5}{|c|}{ Panel (a) } \\
\hline$E_{p 1}$ & $4.2 \mathrm{E}-14$ & $5.5 \mathrm{E}-13$ & $7.8 \mathrm{E}-14$ & $9.8 \mathrm{E}-14$ \\
\hline$E_{p 2}$ & $7.5 \mathrm{E}-14$ & 8.7E-14 & $7.8 \mathrm{E}-14$ & 8.7E-14 \\
\hline$E_{p 3}$ & $1.5 \mathrm{E}-13$ & $7.9 \mathrm{E}-14$ & $6.8 \mathrm{E}-14$ & $4.7 \mathrm{E}-14$ \\
\hline \multicolumn{5}{|c|}{ Panel (b) } \\
\hline$R_{\mathrm{v}}$ & 3.57 & 1.44 & 1.15 & 2.08 \\
\hline
\end{tabular}

(a) Parameters effect; (b) rate of variation $\left(R_{\mathrm{v}}\right)$ related to the parameters.

sponding to an intensity of 1 for $\bar{L}$ and $N_{s}$ (networks 1-9) and is equal to the average permeability $k_{z}$ of these networks.

For each network, Table 4 shows the variation rate $R_{\mathrm{v}}$ of $k_{z}$ related to each parameter, for the three degrees of bedding perpendicular joint density $\left(N_{\mathrm{s}_{i}}\right)$. The influence of the mean stopping capacity of bedding planes $(\overline{\mathrm{SC}})$, the mean perpendicular joint length $(\bar{L})$ and the standard deviation $\left(\sigma_{L}\right)$ notably varies when the density of the networks changes:

- For high-density networks $\left(N_{s_{3}}=60\right)$, these parameters have almost no influence on the permeability $k_{z}$.

- For networks of moderate and low density $\left(N_{\mathrm{s}_{2}}=30\right.$ and $\left.N_{\mathrm{s}_{1}}=15\right)$, the variation of $\overline{\mathrm{SC}}$ can induce an important change in $k_{\mathrm{z}}\left(R_{\mathrm{v}}=2.6\right)$.
Table 4 Detailed analysis of the $k_{z}$ permeability variation: rate of variation $\left(R_{\mathrm{v}}\right)$ related to the geometrical and structural parameters associated to each network density

\begin{tabular}{llll}
\hline Type of network & $p$ & & \\
\cline { 2 - 4 } & $\bar{L}$ & $\sigma_{L}$ & $\overline{\mathrm{SC}}$ \\
\hline Low density $\left(N_{\mathrm{s}}=1.5, D=2.1\right)$ & 1.9 & 1.2 & 2.6 \\
$\begin{array}{l}\text { Intermediate density } \\
\quad\left(N_{\mathrm{s}}=30, D=3.1\right)\end{array}$ & 1 & 1.5 & 2.6 \\
High density $\left(N_{\mathrm{s}}=60, D=4.7\right)$ & 1.3 & 1.1 & 1.2 \\
Without any distinction & 1.45 & 1.2 & 2.1 \\
\hline
\end{tabular}

- For low-density networks only, the mean perpendicular joint length $(\bar{L})$ has a noticeable influence on $k_{z}$ $\left(R_{\mathrm{v}}=1.9\right)$.

\section{Effective permeability tensor}

Fig. 10 shows the main directional components $\left(k_{x}, k_{y}, k_{z}\right)$ of the mean effective permeability tensor for each type of fracture network computed from 200 statistically equivalent simulations.

The main characteristics of the effective permeability tensors determined for each network are the following:

- $k_{x} \geqslant k_{y}$ for all the synthetic networks and the $k_{x} / k_{y}$ ratio can reach a value of 15 when the mean perpendicular joint length $(\bar{L})$ is larger than the elementary dimension 
$\left(\bar{L}=2 D_{\mathrm{e}}\right)$. This result was expected given that the bedding perpendicular joint strike corresponds to the $X$ direction.

- $k_{x}>k_{z}$ for all the synthetic networks, even for a low value of the mean stopping capacity of bedding planes $(\overline{\mathrm{SC}})$.

- For the synthetic networks of low and moderate-density, $k_{\mathrm{y}}>k_{\mathrm{z}}$ with a $k_{\mathrm{y}} / k_{\mathrm{z}}$ ratio such as $2<k_{\mathrm{y}} / k_{\mathrm{z}}<14$.

- For high-density networks $\left(N_{s_{3}}=60\right) k_{y} \approx k_{z}$ in most cases. $k_{y}<k_{z}$ when the mean bedding perpendicular joints length is lower or equal to the elementary volume dimension $\left(\bar{L}=0.5 D_{\mathrm{e}}\right.$ or $\left.\bar{L}=D_{\mathrm{e}}\right)$.

Whatever the analysed synthetic network is, we observe that $k_{x} / k_{y}<10, k_{x} / k_{z}<15$, and $k_{y} / k_{z}<15$, for a given hydraulic aperture.

In consequence, when the effective permeability along one direction $(X, Y$ or $Z$ ) is determined (from direct or indirect measurements), the order of magnitude of the other effective permeability components is known. Obviously, this result is limited to the range of network geometries tested in this work, and to the assumptions regarding the identical hydraulic aperture $a_{\mathrm{h}}$ for both bedding perpendicular joints and bedding planes joints.

\section{Implications for the geometrical and structural properties to assess in the field}

The main geometrical and structural properties that can be measured in the field are the mean stopping capacity of bedding planes $(\overline{\mathrm{SC}})$, the mean $(\bar{L})$ and standard deviation $\left(\sigma_{L}\right)$ of the perpendicular joint length distribution, the mean $(\bar{T})$ and standard deviation $\left(\sigma_{T}\right)$ of the bed thickness distribution, and the bedding perpendicular joint density $\left(N_{s}\right)$ which are related to the numerical parameters used as input in our structural model. Their influence on the components of the effective permeability tensor has been analysed in the preceding section, except for $\bar{T}$ and $\sigma_{T}$, as we considered a constant mean spacing between bedding planes.

The bedding perpendicular joint spacing $(S)$, on the other hand, results from the stochastic processes that control bedding perpendicular joint propagation and mechanical interactions. It ranges between $0.1 D_{\mathrm{e}}$ and $0.54 D_{\mathrm{e}}$ (cf. Fig. 4c). Therefore, we considered three spacing intensity to characterize this parameter (property) according to the measured range of spacing: $S_{1}=0.1-0.24 \mathrm{~m}, S_{2}=0.25-$ $0.39 \mathrm{~m}$, and $S_{3}=0.4-0.54 \mathrm{~m}$.

As we showed that $\sigma_{L}$ has no significant effect on the permeability values, the directional permeability $k_{d}$ are mainly function of $\bar{L}, S, \overline{\mathrm{SC}}$ :

$k_{\mathrm{d}}=f[\bar{L} ; S ; \overline{\mathrm{SC}}]$.

We thus performed a global analysis of the variability of the effective permeability tensors components, with respect to these geometrical and structural parameters (properties) to be assessed from outcrops or borehole measurements. Therefore, we analysed the variance of $k_{d}$ and computed the rate of variation $R_{\mathrm{v}}$ as a function of the above parameters.

- For $k_{x}$, Table 5 shows that the mean bedding perpendicular joint spacing $(S)$, the mean perpendicular joint length $(\bar{L})$ and the mean stopping capacity of bedding planes $(\overline{\mathrm{SC}})$ have a negligible influence. This is related to the bedding plane density $D_{\mathrm{bp}}$, which substantially moderates the sensitivity of $k_{x}$ to the other structural parameters. If the bedding plane spacing is greater, then

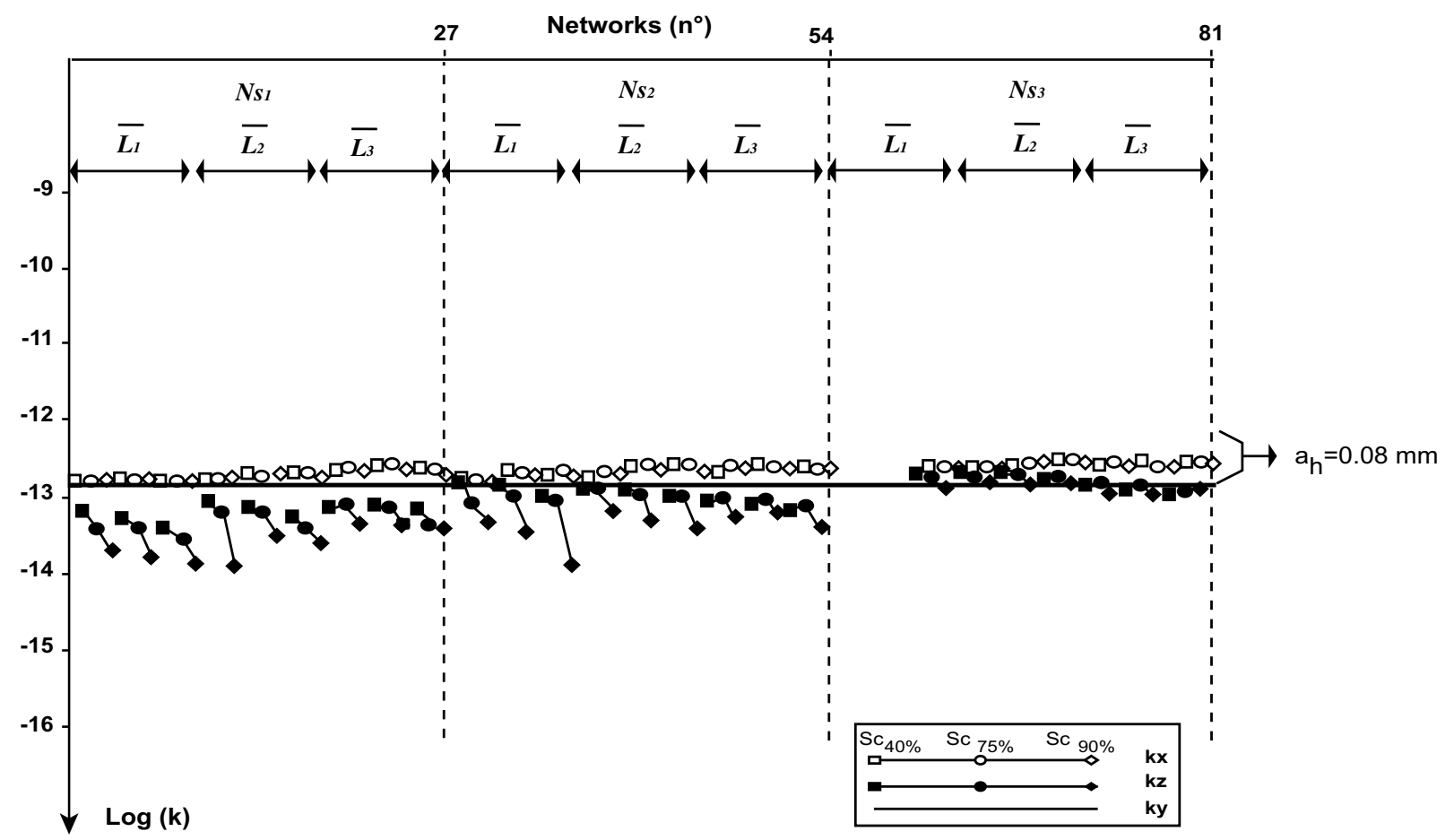

Figure 10 Main directional components of the effective permeability tensor $\left(k_{x}, k_{y}, k_{z}\right)$ calculated for each synthetic network. 
Table 5 Global analysis of the $k_{x}$ permeability variation: (a) Geometrical and structural properties effects; (b) rate of variation $\left(R_{\mathrm{v}}\right)$ related to the geometrical and structural properties

\begin{tabular}{llll}
\hline$E$ & \multicolumn{1}{l}{$p$} & \\
\cline { 2 - 4 } & $S$ & $\bar{L}$ & $\overline{\mathrm{SC}}$ \\
\hline Panel (a) & & & \\
$E_{p 1}$ & $2.1 \mathrm{E}-13$ & $1.8 \mathrm{E}-13$ & $2.1 \mathrm{E}-13$ \\
$E_{p 2}$ & $2.2 \mathrm{E}-13$ & $2.1 \mathrm{E}-13$ & $2.2 \mathrm{E}-13$ \\
$E_{p 3}$ & $2 \mathrm{E}-13$ & $2.4 \mathrm{E}-13$ & $2 \mathrm{E}-13$ \\
Panel (b) & & & \\
$R_{\mathrm{v}}$ & 1.05 & 1.25 & 1.05 \\
\hline
\end{tabular}

Table 6 Global analysis of the $k_{z}$ permeability variation: (a) geometrical and structural properties effects; (b) rate of variation $\left(R_{\mathrm{v}}\right)$ related to the geometrical and structural properties

\begin{tabular}{llll}
\hline$E$ & \multicolumn{3}{l}{} \\
\cline { 2 - 4 } & $S$ & $\bar{L}$ & $\overline{S C}$ \\
\hline Panel (a) & & & \\
$E_{p 1}$ & $1 \mathrm{E}-13$ & $5.5 \mathrm{E}-13$ & $9.8 \mathrm{E}-13$ \\
$E_{p 2}$ & $6 \mathrm{E}-14$ & $8.7 \mathrm{E}-13$ & $8.7 \mathrm{E}-13$ \\
$E_{p 3}$ & $4 \mathrm{E}-14$ & $7.9 \mathrm{E}-13$ & $4.7 \mathrm{E}-13$ \\
Panel (b) & & & \\
$R_{\mathrm{v}}$ & 2.5 & 1.6 & 2.1 \\
\hline
\end{tabular}

the density $D_{\mathrm{bp}}$ of the bedding planes decreases and $k_{x}$ becomes more dependent on $D_{\mathrm{fc}}$, thus on the geometrical and structural properties of the rock mass.

- For $k_{z}$, the effects related to the bedding perpendicular joint spacing $(S)$ and the mean stopping capacity of bedding planes $(\overline{\mathrm{SC}})$ are not negligible anymore (Table 6). Indeed, the range of variations of $S$ can induce changes of almost one order of magnitude in $k_{z}$ and the mean stopping capacity of bedding planes $\overline{\mathrm{SC}}$ can induce a variation around a factor of 2 .

\section{Considerations on the appropriate description of a rock mass to assess the effective permeability tensor}

For a layered fractured rock mass such as the one considered in this study, the following steps may be performed to assess the effective permeability tensor:

(i) The fraction of the rock mass with bedding perpendicular joints must be identified, as well as the density of bedding planes within the elementary volume which strongly influences the $k_{x}$ and $k_{y}$ components.

(ii) The bedding perpendicular joint density $\left(N_{s}\right)$ must be determined as well as possible since it has a predominant effect on the $k_{x}$ and $k_{z}$ components. (iii) The mean bedding perpendicular joint spacing $(S)$ and the mean stopping capacity of the bedding planes $(\overline{\mathrm{SC}})$ must be identified since they can induce more than one order of magnitude changes in the $k_{x}$ and $k_{z}$ components.

(iv) The mean $(\bar{L})$ of the bedding perpendicular joint length distribution, might be measured as it can slightly affect the effective permeability components, but is not a required measurement.

(v) The standard deviation $\left(\sigma_{L}\right)$ of the bedding perpendicular joint length distribution is not an important parameter as it weakly affects the effective permeability components.

One must keep in mind that the aforementioned considerations correspond to a layered fractured rock mass whose characteristics are identical to those of the synthetic networks studied in this paper: At the meter scale, the elementary rock mass should comprise bedding planes with a stopping capacity that ranges between $40 \%$ and $90 \%$ and a bedding perpendicular joint set with a spacing that ranges between $10 \%$ and $50 \%$ of the elementary volume dimension $D_{\mathrm{e}}$.

\section{Implication for a simple determination of the effective permeability tensor}

In the following, we compare the permeability components inferred from the previous formalism (referred hereafter as true permeability component) with the permeability components determined from a simpler analytical model, called the fracture density model.

The hypothesis for this model are the following: (i) The discontinuities have the same hydraulic aperture and (ii) we consider a unique bedding perpendicular joint of density $D$ (cf. Fig. 4a), which participates to the flow along the $X$ and Z-directions.

This model therefore does not account for the spatial organisation of the bedding perpendicular joints and only depends on $D_{\mathrm{bd}}, D$ and $k$.

The directional components of the permeability tensor are expressed as follows:

$k_{\mathrm{y}}=D_{\mathrm{bd}} \times a_{\mathrm{h}} \times k$,

$k_{\mathrm{x}}=\left(D_{\mathrm{bd}}+D\right) \times a_{\mathrm{h}} \times k$,

$k_{\mathrm{z}}=D \times a_{\mathrm{h}} \times k$.

Fig. 11 shows the ratio between the permeability component calculated with this model $\left(k_{1}\right)$ and the true permeability component $\left(k_{2}\right)$.

The values of the true permeability component $k_{x}$ are overestimated by a factor ranging from 1 to 2 . This is an acceptable estimation error regarding the order of magnitude of the cumulative errors due to structural and hydraulic measurements (Renshaw and Pollard, 1994b).

For the $k_{z}$ component, the permeability ratio presents a higher variability:

- For low-density networks, the permeability ratio is ranging between 1.5 and 6 .

- For intermediate density networks, the permeability ratio is lower than 2 except when the mean stopping capacity of the bedding planes $\overline{\mathrm{SC}}=90 \%$. 


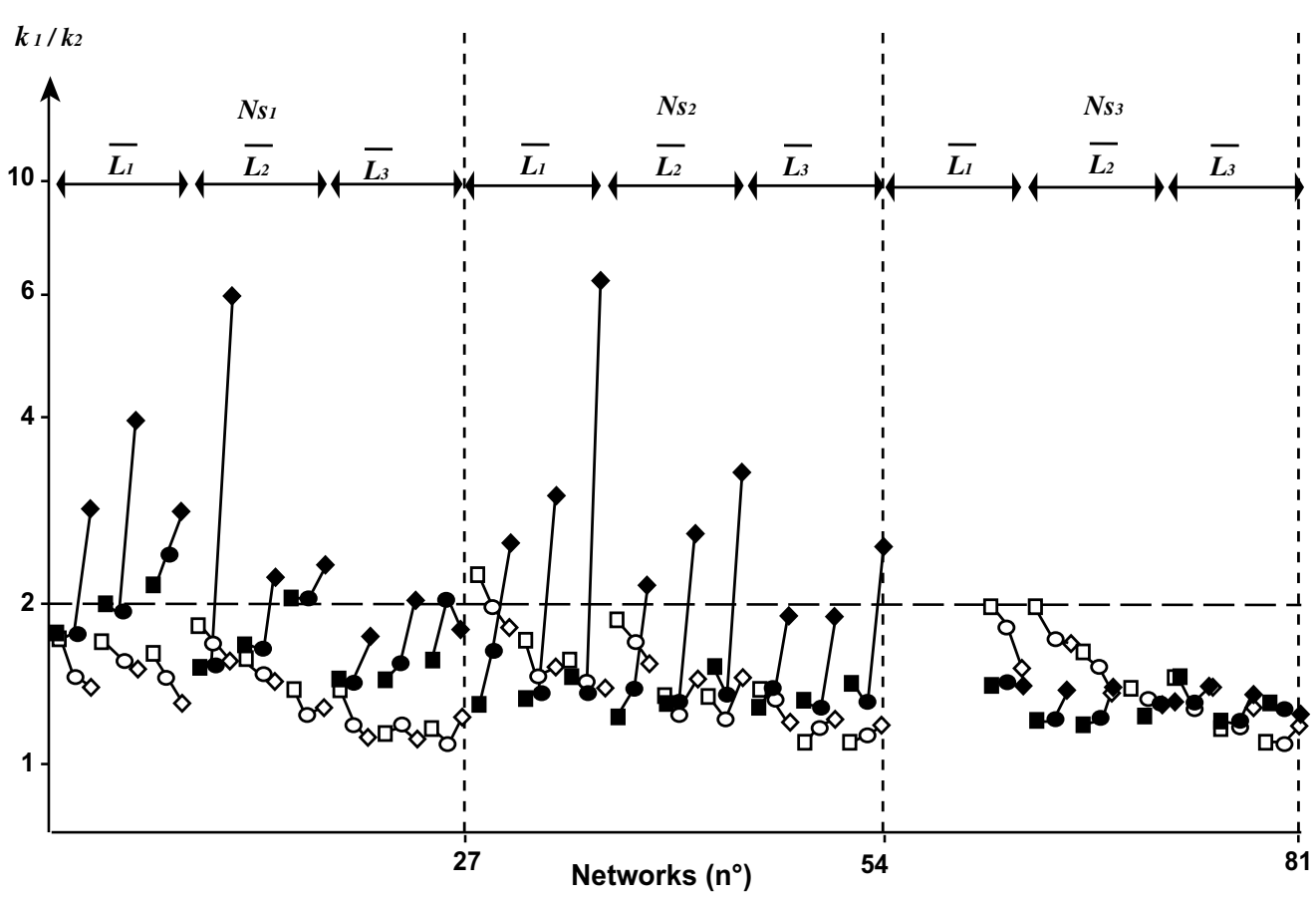

Figure 11 Ratio $\left(k_{1} / k_{2}\right)$ between the true permeability value and the permeability obtained with the fracture density model for all networks. The empty and filled symbols correspond to the ratio of the $k_{x}$ and $k_{z}$ components, respectively.

- For high density networks, the permeability ratio are always lower than 2 .

This reveals that flow simulations to calculate the effective permeability component of a layered fractured rock mass are useful only when a high proportion of bedding perpendicular joints are confined within one stratum, and when the bedding perpendicular joints density is low.

As a result, the knowledge of the bedding perpendicular joint and bedding plane densities within an elementary volume allows assessing the effective permeability tensor of an elementary rock mass, with an acceptable error (lower than one order of magnitude). A very similar methodology described in Nelson (1985) leads to the same conclusion. The estimation of an effective permeability tensor with this model thus appears to be valid, especially in the case of dense fractured networks. Therefore, when a rock mass is studied on outcrops with measurement on crosssections of various orientations, the density of bedding perpendicular joints and bedding planes joints must be determined as well as possible. Then, if the equivalent hydraulic aperture of the discontinuities can be assessed, the effective permeability tensor of the rock mass may be estimated.

\section{Conclusion}

We used a three-dimensional numerical model to generate a wide range of network geometries with realistic crosscutting relationships between bedding perpendicular joints and bedding parallel joints. The effective permeability was considered to be the contributions of both bedding perpendicular joints and bedding parallel joints which we assumed to have the same hydraulic apertures. The geometrical and structural properties of the networks were determined, which allowed estimating the influence of those properties on the effective permeability tensor of a layered fractured rock mass of elementary volume $D_{\mathrm{e}}$.

We showed that some geometrical and structural properties, such as the average spacing between bedding perpendicular joints $(S)$ and the mean stopping capacity of bedding planes $(\overline{\mathrm{SC}})$ can induce more than one order of magnitude changes in the effective permeability values for the range of studied networks. In contrast, the mean and standard deviation of bedding perpendicular joint lengths distribution were found to have a negligible influence on the effective permeability values.

We finally compared the components of the effective permeability tensor calculated with the proposed formalism, with results inferred from a simple analytical model that requires a reduced set of field data. We showed that, when the equivalent hydraulic aperture and the density of bedding perpendicular joints and bedding planes joints are known, the effective permeability tensor of a layered fractured rock mass can be determined within less than one order of magnitude.

As a result, when we aim at determining the effective permeability tensor of a layered fractured rock mass, the structural characterization can be restricted to the measurement of (i) the bedding perpendicular and bedding parallel joint densities, (ii) the crosscutting properties between bedding perpendicular joints and bedding planes, and (iii) the average spacing between bedding perpendicular joints $(S)$.

Then, if the equivalent hydraulic aperture of the discontinuities can be assessed, the effective permeability tensor of the rock mass may be estimated with the proposed fracture density model. 


\section{Acknowledgements}

The authors wish to thank Gh. de Marsily, an anonymous reviewer, and the editor for their helpful comments and suggestions, that greatly helped to improve the present contribution.

\section{References}

Bandis, S.C. 1980. Experimental studies of scale effects on shear strength and deformability of regularly jointed rock. PhD Thesis, Leeds University.

Bear, J., 1972. Dynamics in Porous Media. Elsevier Science, New York.

Belfield, W.C., Sovich, J., 1994. Fracture statistics from horizontal wellbores. In: Canadian SPE/CIM/CANMET International Conference on Advances in Horizontal Well Applications, Calgary, Canada, Paper HWC94-37.

Bouissou, S., Cortes, P., Petit, J.P., Barquins, M., 1999. A new model for the kinetics of jointing in layered rock. A.G.U. Fall Meeting, 13-17 Décembre, San Francisco.

Bour, O., Davy, P., 1997. Connectivity of random fault networks following a power-law length distribution. Water Resources Research 33, 1567-1583.

Castaing, C., Genter, A., Bourgine, B., Chilès, J.P., Wendling, J., Siegel, P., 2002. Taking into account the complexity of natural fracture systems in reservoir single-phase flow modelling. Journal of Hydrology 266, 83-98.

Clauser, C., 1992. Permeability of crystalline rocks. EOS Trans. AGU, 73 (21), 233, 237-238.

Clemo, T.M., Smith, L., 1989. Solute transport in fractured media: dual permeability models. EOS Trans. AGU, 70.

Cravero, M., Fidelibus, C., 1999. A code for scaled flow simulations on generated fracture networks. Computers and Geosciences 25, 191-195.

de Marsily, G., 1985. Flow and transport in fractured rock: connectivity and scale effect. In: IAH, International Symposium on the Hydrogeology of Rocks of Low Permeability, Tucson, Part 1, pp. 267-277.

Doolin, D.M., Mauldon, M., 2001. Fracture hydraulic conductivity normal to bedding in layered rock masses. International Journal of Rock Mechanics and Mining Sciences 38, 199-210.

de Dreuzy, J.R., Davy, P., Bour, O., 2001. Hydraulic properties of two-dimensional random fracture networks following a power law length distribution: 2-Permeability of networks based on log-normal distribution of apertures. Water Resources Research 37 (8), 2079-2095.

Einstein, H.H., Baecher, G.B., 1983. Probabilistic and statistical methods in engineering geology. Rock Mechanics and Rock Engineering 16, 39-72.

Esaki, T., Ikusada, K., Aikawa, A., 1995. Surface roughness and hydraulic properties of sheared rock. In: Myer, L.R., Cook, N.G.W., Goodman, R.E., Tsang, C.-F. (Eds.), Fractured and Jointed Rock Masses. Balkema, Rotterdam, pp. 393-398.

Hakami, E., 1998. Water flow in single rock joints. Licentiate thesis, Lulea University of Technology, 99p.

Helgelson, D.E., Aydin, A., 1991. Characteristics of joints propagation across layer interfaces in sedimentary rocks. Journal of Structural Geology 13, 897-911.

Hsieh, P.A., Neuman, S.P., 1985. Field determination of threedimensional hydraulic conductivity tensor of anisotropic media, 1, theory. Water Resources Research 21, 1655-1665.

Jourde, H., 1998. Simulation d'essais de puits en milieu fracturé à partir d'un modèle discret basé sur les lois mécaniques de fracturation. Validation sur sites expérimentaux. PhD Thesis, Montpellier University, 192p.
Jourde, H., Pistre, S., Bidaux, P., 2002a. Flow behavior in a dual fracture network. Journal of Hydrology 266, 99-119.

Jourde, H., Aydin, A., Durlofski, L., 2002b. Upscaling permeability of fault zones in porous sandstone: from field measurement to numerical modelling. AAPG Bulletin 86 (7), 1187-1200.

Josnin, J.Y., Jourde, H., Fenart, P., Bidaux, P., 2002. A fast and efficient hybrid model to generate $3 D$ fracture networks in layered rocks. Canadian Journal of Earth Sciences 39, 14431455.

Ladeira, F.L., Price, N.J., 1981. Relationship between fracture spacing and bed thickness. Journal of Structural Geology 3 (2), 179-183.

Lee, S.H., Lough, M.F., Jensen, C.L., 2001. Hierarchical modeling of flow in naturally fractured formations with multiple length scales. Water Resources Research 37 (3), 443-455.

Long, J.C.S., Billaux, D.M., 1987. From field data to fracture network modeling: an example incorporating spatial structure. Water Resources Research 23, 1201-1216.

Long, J.C.S., Remer, J.S., Wilson, C., Witherspoon, P.A., 1982. Porous media equivalent for network of discontinuous fractures. Water Resources Research 18, 645-658.

Long, J.C.S., Witherspoon, P.A ., 1985. The relationship of the degree of interconnection to hydraulic conductivity in fracture networks. Journal of Geophysical Research 90 (B4), 3087-3098.

Margolin, G., Berkowitz, B., Scher, H., 1998. Structure, flow and generalized conductivity scaling in fracture networks. Water Resources Research 34 (9), 2103-2121.

Mania, J., Broquet, P., Rampnoux, N., 1998. Rôle de la fracturation dans la détermination de la conductivité hydraulique des calcaires - Apport des méthodes directes et indirectes. Bulletin de la Société Géologique de France 169 (6), 765-773.

Marret, R., Ortega, O., Kelsey, C., 1999. Extent of power-law scaling for natural fractures in rock. Geology 27 (9), 799-802.

Massonat, G., 1998. Des difficultés de la caractérisation et de la modélisation des réservoirs fracturés. Bulletin de Centres de Recherches Exploration-Production Elf Aquitaine 18, 1.

Massonat, G., Manisse, E., 1994. Modélisation des réservoirs fracturés et recherche des paramètres équivalents: étude de l'anisotropie verticale de perméabilité. Bulletin de Centres de Recherches Exploration-Production Elf Aquitaine 18 (1), 171198.

Narr, W., Suppe, J., 1991. Joint spacing in sedimentary rocks. Journal of Structural Geology 3, 1037-1048.

Nelson, R.A., 1985. Geological Analysis of Naturally Fractured Reservoirs. Gulf Publishing Company, USA.

Oda, M., 1985. Hydraulic conductivity tensor for discontinuous rock mass. Geotechnique 35, 483-495.

Odling, N.E., 1992. Network properties of a two-dimensional natural fracture pattern. Pure and Applied Chemistry 138, 95114.

Paillet, F.L., 1985. Problem in fractured-reservoir evaluation and possible routes to their solution. The Log Analyst 26, 26-41.

Panda, B.B., Kulatilake, P.H.S.W., 1999. Effects on joint geometry and transmissivity on jointed rock hydraulics. Journal of Engineering Mechanics-ASCE 125 (1), 51-59.

Petit, J.P., Massonat, G., Pueo, F., Rawnsley, K.D., 1994. Rapport de forme des fractures de mode I dans les roches stratifiées: une étude de cas dans la bassin permien de Lodève (France). Bulletin de Centres de Recherches Exploration-Production Elf Aquitaine 18, 212-229.

Pavlovic, N., 1998. Principles of numerical modelling of jointed rock mass. Mechanics of Jointed and Faulted Rock. Balkema ed, Rotterdam, pp. 311-316.

Pollard, D., Aydin, A., 1988. Progress in understanding jointing over the past century. Geological Society of America Bulletin 100, 1181-1204.

Price, N.J., Cosgrove, J.W., 1990. Analysis of Geological Structure. Cambridge University Press. 
Renshaw, C.E., Pollard, D.D., 1994a. Are large differential stresses required for straight fracture propagation paths? Journal of Structural Geology 16 (6), 817-822.

Renshaw, C.E., Pollard, D.D., 1994b. Numerical simulation of fracture set formation: a fracture mechanics model consistent with experimental observations. Geophysical Research Letters 99 (B5), 9359-9372.

Rives, T., Razack, M., Petit, J.P., Rawnsley, K.D., 1992. Joint spacing: analogue and numerical simulations. Journal of Struc tural Geology 16 (3), 419-423.

Sagar, B., Runchal, A., 1982. Hydraulic conductivity of fractured rock: effect of fracture size and data uncertainties. Water Resources Research 18 (2), 266-274.
Segall, P., Pollard, D.D., 1983. Joint formation in granitic rock of the Sierra Nevada. Geological Society of America Bulletin 94, 563-575.

Schulze-Makuch, D., Carlson, D.A., Cherkauer, D.S., Malik, P., 1999. Scale dependency of hydraulic conductivity in heterogeneous media. Groundwater 37 (6), 904-919.

Snow, D.T., 1969. Anisotropic hydraulic conductivity of fractured media. Water Resources Research 5, 1273-1279.

Wen, X.H., Kung, C.S., Cvetkovic, V., 1991. The inference of geological structure on the radionuclide mass arrival at Finnsjön. Paper presented at the International Conference on Modeling Groundwater Flow and Pollution, Int Assoc of Hydrol Sci, Nanjing, China.

Wilson, 1970. An investigation of laminar flow in fractured porous media. PhD thesis, University of California, Berkeley. 